REVES - Revista Relações Sociais, Vol. 04 N. 04 (2021)

https://periodicos.ufv.br/reves

elSSN: $2595-4490$

REVES-ReVista Relacōes Sociais (eISSN 2595-4490)

\title{
Um breve panorama da produção de itens para avaliação da qualidade da Educação Superior em 2019
}

\section{A brief overview of the production of items for quality assessment of higher education in 2019}

Atair Silva de Sousa

http://orcid.org/0000-0002-1355-8797

Faculdade de Educação/Universidade de São Paulo (USP)/Brasil atair.sousa@usp.br

Article Info:

Article history: Received 2021-07-20

Accepted 2021-09-29

Available online 2021-09-29

doi: 10.18540/revesvl4iss4pp13216-01-12e

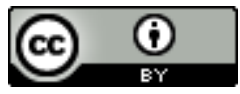

Resumo. Neste estudo foi realizada uma breve análise dos processos que envolvem a produção de itens produzidos para a prova do Exame Nacional de Desempenho do Estudante (ENADE) no âmbito do Sistema de Avaliação da Educação Superior (SINAES) cujo propósito é a avaliação da qualidade da Educação Superior em 2019. O objetivo foi analisar os processos da produção de itens para esta prova levando em conta o aproveitamento deles para o Banco Nacional de Itens da Educação Superior (BNI-ENADE), além de propor medidas pedagógicas que possam trazer melhorias para esses processos. Foram realizadas uma pesquisa bibliográfica documental e uma busca de dados, referentes à produção de itens para o BNIENADE, disponibilizados pelo Instituto Nacional de Estudos e Pesquisa Educacionais (INEP). Os resultados mostraram um percentual de aproveitamento de itens dentro da normalidade e, além disso, percentual positivo de eficiência deste banco de itens para os cursos avaliados nessa edição. Por outro lado, os resultados também apontaram fragilidades no aproveitamento de itens para determinadas áreas de conhecimento. Com isso, foi possível apontar possíveis intervenções que possam trazer melhorias ao processo de produção de itens para esse banco de itens.

Palavras-chave: Educação Superior. Banco Nacional de Item. Políticas Educacionais. ENADE.

Abstract. In this study, a brief analysis of the processes that involve the production of items produced for the test of the National Exam of Student Performance (ENADE) was carried out in the scope of the System for Evaluation of Higher Education (SINAES) whose purpose the evaluation of the quality of Higher Education in 2019. The objective was to analyze the processes of the production of items for this test taking into account their use for the National Bank of Items of Higher Education (BNIENADE), and to propose pedagogical measures that can bring improvements to these processes. It was performed a documental bibliographic research and a search 
for data, regarding the production of items for BNI-ENADE, made available by the National Institute for Educational Studies and Research (INEP). The results showed a percentage of use of items within normality and, furthermore, a positive percentage of efficiency of this bank of items for the courses assessed in this edition. On the other hand, the results also indicated weaknesses in the use of items for certain areas of knowledge. Thus, it was possible to point out possible interventions that can bring improvements to the process of items production for this bank of items

Keywords: Higher Education. National Item Bank. Educational Policies. ENADE.

\section{Introdução}

Recentemente, viu-se crescer o interesse pelo assunto da produção de itens para avaliação em larga escala. $O$ debate sobre este tipo de avaliação tem ganhado relevância em razão da abrangência e importância que este tipo de avaliação ocupa no cenário das políticas educacionais no país, principalmente no que se refere à avaliação da qualidade da educação. Em relação à Educação Superior, o primeiro parágrafo do art. $5^{0}$ da Lei de criação do Sistema Nacional de Avaliação da Educação Superior (SINAES) - Lei no 10.861, de 14 de abril de 2004 - traz em seu âmbito, o vínculo do Exame Nacional de Desempenho de Estudantes (ENADE) com esse sistema de avaliação (BRASIL, 2004).

O objetivo do ENADE é avaliar a trajetória dos estudantes dos cursos de graduação, em relação aos conteúdos programáticos, habilidades e competências adquiridas em sua formação. No âmbito da prova do ENADE, o Banco Nacional de itens da Educação Superior (BNI-ENADE) se caracteriza como um instrumento das diretrizes da avaliação da Educação Superior e, por conseguinte, inserido nas atribuições direcionadas pela lei de criação do SINAES.

Diante do exposto, o presente estudo busca responder a seguinte questão: que medidas pedagógicas poderiam contribuir com melhorias nos processos de produção de itens implicando em melhor aproveitamento deles para o banco nacional de tens.

Para este estudo, a eficiência é definida como: a razão entre o número de itens inseridos no BNI-ENADE para cada curso ou área naquela edição do ENADE e o número de itens elaborados para cada curso ou área. A equação (1) representa o modelo de como efetuar o cálculo da eficiência:

$$
\mathrm{E}=\frac{(\mathrm{Ia}-\mathrm{Ip})}{\mathrm{Ie}}
$$

na qual: "E" representa a eficiência; "la" o número de itens aceitos (aprovados); "Ip" o número de itens selecionados para prova e; "le" o número de itens elaborados. Este é um cenário esperado, embora possa acontecer o fato de que dentre os itens aceitos não seja possível extrair os 30 itens de prova, ou no caso da Formação Geral 10 itens. Neste caso, buscam-se itens existentes no banco de itens para completar o número de itens de prova.

Neste trabalho são apresentados os principais pontos explicativos na elaboração de itens para a prova do ENADE. Com isso, para este estudo, o objetivo específico foi: propor medidas pedagógicas que possam trazer melhorias no aproveitamento de itens para o banco nacional de itens. Neste trabalho foi utilizado um método de estudo qualitativo/quantitativo. Foi realizada uma análise documental com a leitura e análise de informações disponibilizadas em sítios oficiais, como por 
exemplo, do Ministério da Educação (MEC) e do INEP, que tratam da legislação vigente sobre a avaliação da qualidade da Educação Superior no Brasil.

Este trabalho está organizado em quatro seções, além desta introdução. $\mathrm{Na}$ segunda seção são apresentados os processos envolvidos no banco nacional de itens. Na terceira seção são apresentados os procedimentos metodológicos. $\mathrm{Na}$ quarta seção é apresentada uma análise, discussão e conclusão dos resultados, apontando propostas de intervenções pedagógicas. Na última seção são realizadas as considerações finais, fazendo uma síntese deste estudo.

\section{O BNI como processo de qualidade na instrumentação da avaliação da educação}

O BNI define-se, como uma coleção de Itens de testes de natureza específica - organizada segundo determinados critérios - disponíveis para a construção de instrumentos de avaliação (BRASIL, 2020). A manutenção do BNI depende da entrada constante de itens de qualidade. Para tanto, educadores e pesquisadores da educação brasileira são chamados a colaborar nessa construção, elaborando Itens que possam fazer parte desse banco.

O guia de elaboração e revisão de Itens apresenta as orientações do INEP para a construção e revisão de itens para testes de avaliação em larga escala, considerando a literatura especializada na área e, se estrutura da seguinte forma: definições e conceitos; estrutura do item de múltipla escolha; etapas para elaboração de item; especificações para apresentação do item; etapas de validação de item; protocolo de revisão de item (INEP, 2019c).

As avaliações em larga escala distinguem-se das avaliações internas, sendo que estas são elaboradas pelo professor ou pela própria Instituição para avaliar e propor alternativas no âmbito da sala de aula ou da Instituição. Enquanto isso, as avaliações em larga escala são elaboradas por um órgão externo à Instituição com a finalidade de fazer juízos de valor e propor alternativas em âmbito mais amplo que o da Instituição (INEP, 2020). É neste contexto das avaliações de larga escala que a implementação do BNI se apresenta como uma solução para a elaboração e montagem das provas. No Quadro 1 são apresentados os instrumentos avaliativos que utilizam o BNI.

Quadro 1. Processos dos instrumentos avaliativos do BNI.

\begin{tabular}{|c|c|}
\hline \multicolumn{2}{|c|}{ Processo do BNI } \\
\hline Instrumento avaliativo & Nível educacional \\
\hline $\begin{array}{c}\text { Provinha Brasil; Sistema Nacional de Avaliação da } \\
\text { Educação Básica - SAEB. }\end{array}$ & Educação Básica \\
\hline Programa Internacional de Avaliação de Alunos - PISA. & Educação Básica \\
\hline Exame Nacional do Ensino Médio - ENEM. & Educação Básica \\
\hline $\begin{array}{c}\text { Exame Nacional de Desempenho de Estudantes - ENADE. } \\
\text { Adultos - ENCCEJA. }\end{array}$ & Educação Superior \\
\hline Revalional de Certificação de Competên Diplomas Médicos - REVALIDA. & Educação Básica \\
\hline Certificado de Proficiência na Língua Brasileira de Sinais - \\
PROLIBRAS. & Educação Superior \\
\hline Certificado de Proficiência em Língua Portuguesa - CELPE- \\
BRAS.
\end{tabular}

Fonte. Elaborado pelo autor. 
Uma atividade necessária para que essas avaliações aconteçam é a manutenção de um banco de itens que ofereça subsídios para construir os testes. A existência de um BNI no INEP é necessária para que se tenha uma quantidade expressiva de Itens com comprovada qualidade técnico-pedagógica e psicométrica para comporem os testes de uma avaliação em larga escala. O BNI define-se, portanto, como uma coleção de itens de testes de natureza específica - organizada segundo determinados critérios - disponíveis para a construção de instrumentos de avaliação. A manutenção do BNI depende da entrada constante de itens de qualidade. Para tanto, educadores e pesquisadores da educação brasileira são chamados a colaborar nessa construção, elaborando itens que possam fazer parte desse banco (INEP, 2019a). Em atividades dessa natureza, a experiência docente é de fundamental importância para que se possam elaborar itens em consonância com o contexto educacional. (INEP, 2010).

O BNI da Educação Superior, criado em 2010 tem por objetivo reunir questões de qualidade técnica que permitam ao INEP avaliar por meio do exame o conhecimento dos estudantes em relação aos conteúdos programáticos, habilidades e competências previstas nas Diretrizes Curriculares Nacionais (DCNs) dos cursos de graduação. O INEP busca qualificar o exame com a construção de Itens elaborados por profissionais experientes. O BNI é um sistema importante na construção dos instrumentos avaliativos do INEP. Isso porque fornece a segurança necessária ao processo de construção das provas, confiabilidade e garante maior participação da comunidade acadêmica na construção dos Itens (INEP, 2019e).

Para Soares; Hora; Caseiro (2016, p.5) "a criação, implementação e gestão do BNI-ENADE foi uma iniciativa do INEP para possibilitar a melhoria dos processos que envolvem a elaboração dos instrumentos de avaliação aplicados neste Exame". Este banco permitiu a ampliação da participação da comunidade acadêmica nas diversas etapas de construção dos instrumentos, além de aperfeiçoar o investimento na elaboração de itens.

O ano de 2010 é um momento importante em ações desenvolvidas voltadas para a composição da prova do ENADE, tendo em vista que foi neste ano a ocorrência da implantação do BNI-ENADE. Segundo Campos (2013) a criação desse banco se deu no trâmite institucional. A autora se refere ao BNI como um instrumento institucional, modelado para além da produção de itens para comporem as provas. Ela defende que o BNI possui uma dupla missão tal que, "[...] é ao mesmo tempo um banco de Itens, como um banco de elaboradores e revisores de Itens. No caso da Diretoria de Avaliação da Educação Superior (DAES), este último tem a nomenclatura de Cadastro de Elaboradores e Revisores de Itens da Educação Superior - CERES.". (CAMPOS, 2013, p. 16-17).

O BNI-ENADE consiste de um sistema computacional no qual permanecem armazenados os itens de testes de natureza específica que podem ou não ser utilizados nas provas do ENADE realizadas pelo INEP. Estes itens são organizados seguindo critérios estipulados por cada edição do exame (CAMPOS, 2013). Este banco é um acervo de itens elaboradas a partir de matrizes de conteúdo, competências e habilidades, pré-definidos, que permitem a montagem de provas que buscam estimar com a maior precisão possível a proficiência dos estudantes com relação aos conteúdos de seus respectivos cursos de graduação, conforme previsto no art. 5을 Lei no 10.861/2004 (INEP, 2019b).

Portanto, pode-se observar que há uma sequência lógica e adequada para os procedimentos necessários ao refinamento e lapidação de um item para compor a 
prova do ENADE. Todas essas etapas estão previstas baseando-se nos princípios da segurança e qualidade do instrumento de avaliação da Educação Superior.

\section{Procedimentos Metodológicos}

Para este estudo o método de pesquisa utilizado foi do tipo qualitativo/quantitativo. O método qualitativo está em relevo pelo predomínio de análises, diálogos e discussões das assertivas contextualizadas aos aspectos pedagógicos do BNI-ENADE. Os dados coletados são secundários e de natureza quantitativa - valores inteiros relativos ao número de itens do BNI-ENADE do INEP 2019.

A fonte de dados quantitativos utilizados neste estudo teve sua origem em Relatório de 2019 do INEP, disponibilizados pela Ouvidoria do INEP, cuja solicitação teve como número de protocolo: 23546.025418/2021-09, via portal do fala.br (INEP, 2021).

Foram utilizadas ferramentas da estatística descritiva simples por motivo de coleta de dados que tem a sua natureza quantitativa, sejam na elaboração de tabelas, quadros, tabelas, dados percentuais ou processos de contagem. Os dados são do tipo secundário por terem sido produzidos, seja pelo INEP, seja por autores da área educacional.

Com esse entendimento, tomou-se como objeto a análise de dados e informações no ano de 2019, com a premissa de melhor mapear as ações previstas no processo de capacitação dos colaboradores do BNI-ENADE. Observando-se as especificidades da base, optou-se pela utilização dos dados do INEP, em função desse órgão apresentar coletas de dados de todo o processo e atividades do BNIENADE.

Os dados coletados foram dispostos em tabelas e gráficos transformados em valores inteiros absolutos, tanto do quantitativo de itens quanto das percentagens relativas às eficiências do aproveitamento de itens. Este procedimento pode facilitar futuras comparações entre a edição do ano de 2019 e as que o sucederem. Neste caso, visualizar a evolução de itens aprovados, se de fato, evoluíram em quantidade e qualidade.

\section{Resultados e Discussão}

Elucidadas as etapas de tratamento e abastecimento do BNI-ENADE com itens provenientes daquela edição do ENADE, é proposta uma reflexão e avaliação de todos os processos e etapas concluídas. Com isso, é possível propor novas intervenções que possam corrigir ou mesmo agregar novos conhecimentos que tragam melhorias aos processos. E, com isso, novas metodologias podem surgir e trazer melhorias aos instrumentos de avaliação da Educação Superior. A seguir são postas algumas dessas avaliações e reflexões que foram realizadas ao longo das edições desse exame.

Com a implantação desse sistema de avaliação da Educação Superior, foi observada a ampliação da participação da comunidade acadêmica na construção dos instrumentos, respeitando os princípios estabelecidos pela lei de criação do SINAES. Como pôde ser notada, a construção de um acervo de itens com qualidade técnica, pedagógica e psicométrica, capazes de alcançar com precisão a proficiência dos estudantes em relação aos aspectos previstos nas DCNs dos cursos de graduação do país. Um processo continuado de melhoria no fluxo de processo com 
inclusão de novas etapas, tais como: revisão final, realizada pela CAA e revisão de sensibilidade, realizada pela CAT (CERRI, 2016).

A Tabela 1 apresenta o quantitativo de itens elaborados, aceitos e descartados por modalidade (Bacharelado, Tecnológico e Formação Geral), na edição do ENADE 2019.

Tabela 1 Aproveitamento do BNI-ENADE 2019.

\begin{tabular}{cc|c|c|c}
\hline \multicolumn{5}{c}{ Aproveitamento do BNI-ENADE em 2019. } \\
\hline Modalidade & le & la & Id & $\mathrm{E}(\%)$ \\
\hline Bacharelado & 3.542 & 2.310 & 1.232 & 65 \\
\hline Tecnológico & 883 & 480 & 403 & 54 \\
\hline Formação Geral & 58 & 29 & 29 & 50 \\
\hline Total & 4.483 & 2.819 & 1.664 & 63 \\
\hline
\end{tabular}

Fonte: (INEP, 2021).

O resultado do aproveitamento total aponta para um número satisfatório, levando em consideração de que, para cada prova, são utilizados 40 itens, sendo 30 itens de Conhecimentos Específicos e 10 itens de Formação Geral. Contudo, é necessário estar atento ao abastecimento do BNI-ENADE e desenvolver propostas contínuas de aprimoramento nos processos de capacitação para que os resultados não sofram declínio.

Em relação à distribuição dos itens apontados na tabela 1 e aos cursos do ciclo do ENADE de 2019, os gráficos e as tabelas a seguir, dão conta de como se dá a distribuição em termos de quantidade e qualidade. É possível inferir que o processo de abastecimento do BNI-ENADE ocorre de forma dinâmica e continua, de tal modo que, as metodologias utilizadas nos cursos de capacitação dos colaboradores, têm ocorrido de forma positiva e não se configura de um processo pronto e acabado.

Com isso, ratifica-se a necessidade de manutenção e continuidade dos processos de melhorias na formação cada vez mais atualizadas dos colaboradores. $\mathrm{O}$ alerta sinaliza para dificuldades de docentes de algumas áreas em elaborar itens que atendam ao padrão exigido para avaliação em larga escala. Por outro lado, ratifica-se a afirmativa de que a capacitação pedagógica se faz ainda necessária no processo de elaboração e revisão de itens, não só em função de novos componentes desse grupo de docentes, mas também pela necessidade de novas investidas de intervenções pedagógicas nesse processo. Embora o BNI-ENADE esteja em uma em fase de pleno abastecimento de itens, ainda não tem apresentado indícios de colapso no sentido de carência generalizada de itens, mas é preciso estar atento para essa possibilidade no futuro próximo.

No Quadro 2 são apresentados os 29 cursos avaliados na edição do ENADE de 2019 e a área de Formação Geral. 


\section{Quadro 2. Cursos avaliados e área de Formação Geral - ENADE 2019.}

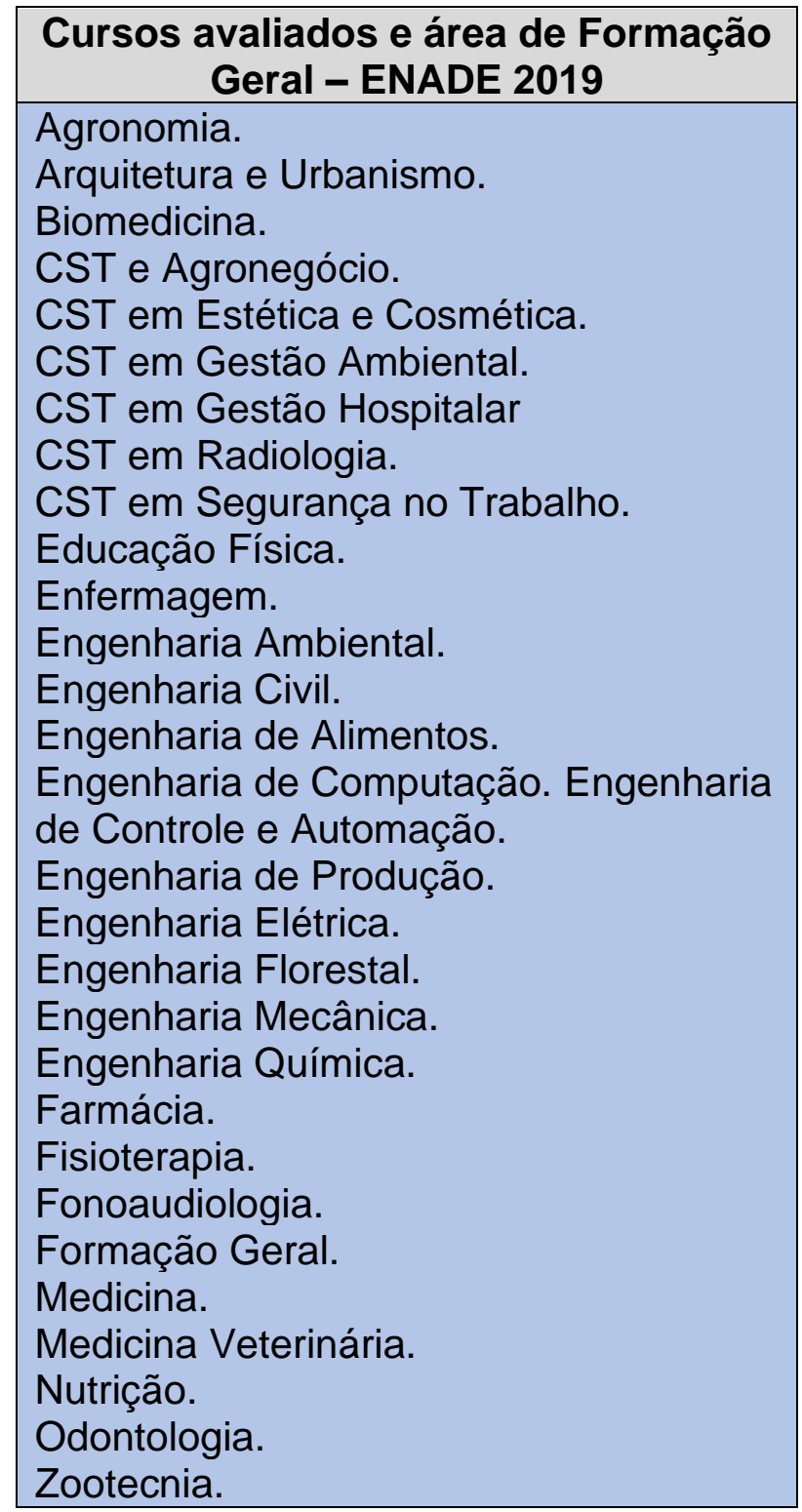

Fonte: (INEP, 2021).

Na Figura 1 estão apresentados os dados referentes aos números de itens elaborados, aceitos e descartados para cada curso avaliado na edição do ENADE de 2019. Os dados apresentados na Figura 1 mostram que para maioria dos cursos, é produzido pelo menos três vezes o número de itens exigidos para comporem a prova de cada curso. Para todos os cursos avaliados nesta edição do ENADE foram aprovados (aceitos) um número de itens que é maior que 30. Isso significa que, subtraído o número de itens que comporão a prova, os demais serão inseridos no BNI-ENADE, gerando um saldo positivo neste banco para todos os cursos avaliados. Ou seja, há de fato evidências de resultados positivos em função de ações afirmativas assinaladas nos cursos de capacitação para elaboradores e revisores de itens. Pode-se verificar que, de fato, necessidades na continuidade de aprimoramentos nos processos pedagógicos de treinamentos e capacitação dos colaboradores. 
Figura 1. Número de itens elaborados, aceitos e descartados por curso ENADE 2019.

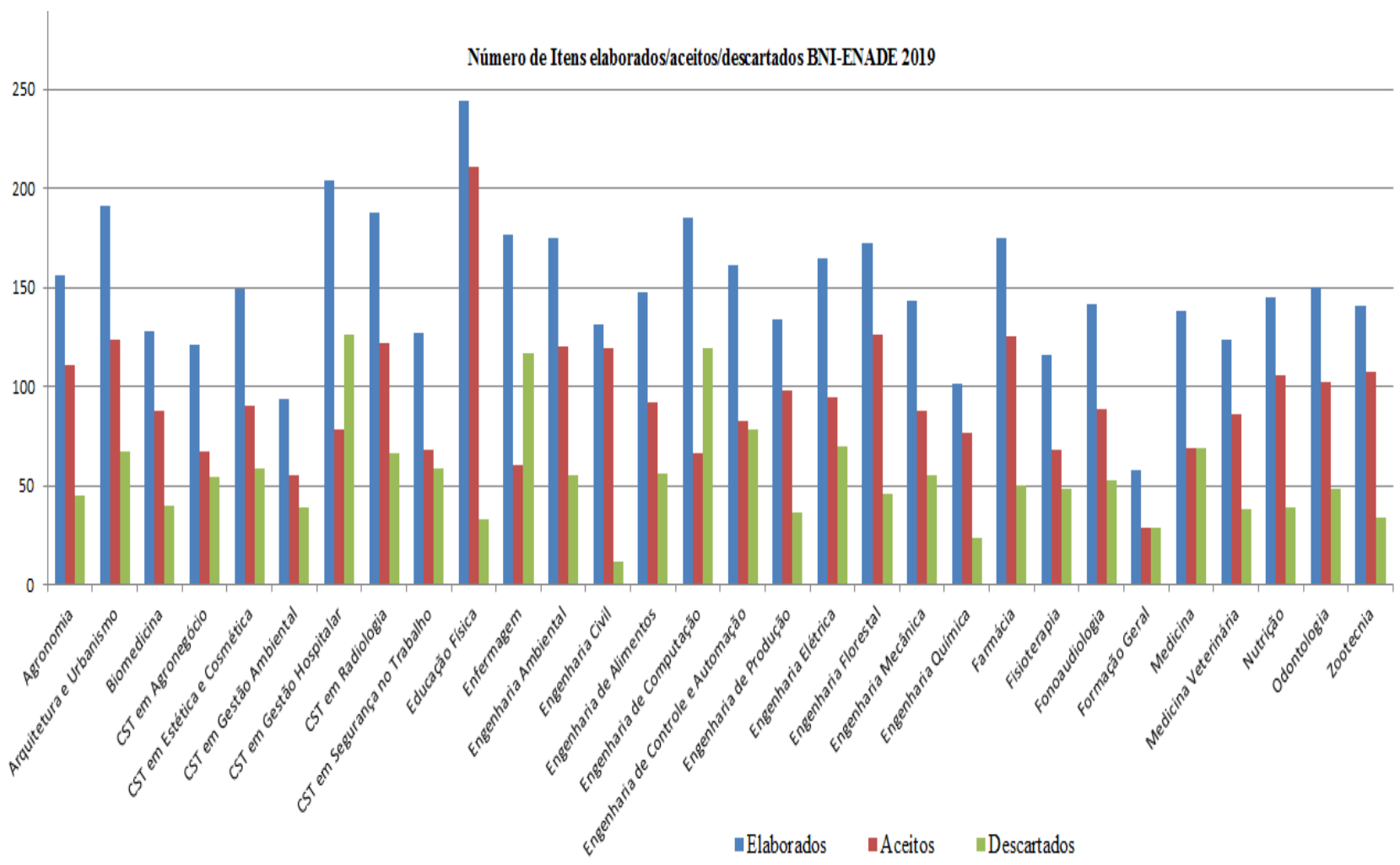

Fonte. (INEP, 2021).

Contudo, os dados sinalizam para números alarmantes de itens descartados em determinados cursos, como por exemplo, no curso de Enfermagem, CSTGestão Hospitalar e Engenharia de Computação. O alerta sinaliza para dificuldades de docentes destas áreas em elaborar itens que atendam ao padrão exigido pelo INEP para que eles componham o BNI-ENADE. Por outro lado, ratifica-se a afirmativa de que a capacitação pedagógica se faz ainda necessária no processo de elaboração e revisão de itens, não só em função de novos componentes desse grupo de docentes, mas também pela necessidade de novas investidas de intervenções pedagógicas nesse processo. Embora o BNI-ENADE esteja em uma em fase de pleno abastecimento de itens, ainda, não tendo apresentado indícios de colapso no sentido de carência generalizada de itens, é preciso estar atento para essa possibilidade no futuro próximo. Os principais motivos pelos quais Itens são descartados pelos membros das Comissões Assessoras de Áreas (CAAs) e pela equipe da CGENADE/INEP, estão apresentados no Quadro 3. 
Quadro 3. Motivos de descarte de tens.

\begin{tabular}{|c|c|}
\hline \multicolumn{2}{|r|}{ ncipais motivos de descartes de itens. } \\
\hline Motivo & cativa \\
\hline Implausibilidade. & $\begin{array}{l}\text { tratores que favoreçam a resolução median } \\
\text { jiocínio por exclusão. }\end{array}$ \\
\hline dificuldade. & $\begin{array}{l}\text { Aquém do adequado ou muito simples/óbvio para } \\
\text { avaliar concluintes de cursos de graduação. }\end{array}$ \\
\hline $\begin{array}{l}\text { Abordagem } \\
\text { conhecimento. }\end{array}$ & $\begin{array}{l}\text { Muito específico; mais próximos das linha } \\
\text { especializadas de pesquisa na pós-graduação. }\end{array}$ \\
\hline $\begin{array}{l}\text { Uso de } \\
\text { estatísticos. }\end{array}$ & $\begin{array}{l}\text { Informações (centrais, conceitos, abordagem teórica) } \\
\text { defasadas, ultrapassadas ou controversas que } \\
\text { comprometem a validade das afirmacões. }\end{array}$ \\
\hline s & $\begin{array}{l}\text { a em língua estrangeira para prova em qu } \\
\text { a adoção de outro idioma. }\end{array}$ \\
\hline n. & $\begin{array}{l}\text { mente semelhante a outro } \\
\text { BNI. }\end{array}$ \\
\hline $\begin{array}{l}\text { a } \\
\text { ismos. }\end{array}$ & ínima correspondente \\
\hline $\begin{array}{l}\text { Ocorrência de falhas } \\
\text { técnicas ou fuga ao } \\
\text { modelo proposto pelo } \\
\text { INEP para as provas do } \\
\text { ENADE. }\end{array}$ & $\begin{array}{l}\text { Item solicita a escolha de opção incorreta. } \\
\text { Item de asserção-razão fora do padrão. } \\
\text { Item apresenta redação sem coesão e/ou coerência } \\
\text { entre os elementos, estando, no todo, prejudicado. } \\
\text { Item apresenta distratores excludentes entre si. } \\
\text { Item apresenta distratores óbvios, que não dependem } \\
\text { de formação em curso de graduação para serem } \\
\text { julgados. } \\
\text { Item depende de análise de gráfico/imagem/tabela que } \\
\text { está ausente. }\end{array}$ \\
\hline $\begin{array}{lr}\text { Item } & \text { apresenta } \\
\text { problemas } & \text { de } \\
\text { sensibilidade, } & \text { estando, }\end{array}$ & $\begin{array}{l}\text { Item aborda o tema de forma preconceituosa. } \\
\text { Item apresenta problemas relacionados a qu } \\
\text { político-partidárias. }\end{array}$ \\
\hline $\begin{array}{l}\text { Falta de } \\
\text { correspondência com a }\end{array}$ & scursivo \\
\hline
\end{tabular}

Fonte: Elaborado pelo autor.

Nesta edição da prova ENADE os cursos de Biomedicina e Engenharia Mecânica tiveram o mesmo número de itens aceitos, 88. Embora houvesse a inserção de 58 itens para cada um deles no BNI-ENADE, considerando que 30 itens foram selecionados para a prova, as eficiências foram de $45 \%$ e $41 \%$, respectivamente. Outra ocorrência interessante foi entre os cursos de Engenharia Ambiental e Engenharia de Produção, na qual ambos tiveram a mesma eficiência, $51 \%$. Porém, o primeiro teve a inserção de 90 itens no banco e o segundo 68 itens no banco. Estas ocorrências estão relacionadas ao fato de que para o cálculo da eficiência o número de itens elaborados é levado em consideração, conforme demostrado na equação (1). Por fim, para esta edição da prova ENADE, a eficiência total foi de $43 \%$, conforme mostrado na Tabela 3. 
Tabela 3. Eficiência de itens do BNI-ENADE 2019.

Eficiência do BNI-ENADE em 2019 por curso e área

\begin{tabular}{l|c}
\hline \multicolumn{1}{c|}{ Curso/área } & E(\%) \\
\hline Agronomia & 52 \\
\hline Arquitetura e Urbanismo & 49 \\
\hline Biomedicina & 45 \\
\hline CST em Agronegócio & 31 \\
\hline CST em Estética e Cosmética & 40 \\
\hline CST em Gestão Ambiental & 27 \\
\hline CST em Gestão Hospitalar & 24 \\
\hline CST em Radiologia & 49 \\
\hline CST em Segurança no Trabalho & 30 \\
\hline Educação Física & 74 \\
\hline Enfermagem & 17 \\
\hline Engenharia Ambiental & 51 \\
\hline Engenharia Civil & 68 \\
\hline Engenharia de Alimentos & 42 \\
\hline Engenharia de Computação & 19 \\
\hline Engenharia de Controle e Automação & 33 \\
\hline Engenharia de Produção & 51 \\
\hline Engenharia Elétrica & 39 \\
\hline Engenharia Florestal & 56 \\
\hline Engenharia Mecânica & 41 \\
\hline Engenharia Química & 47 \\
\hline Farmácia & 54 \\
\hline Fisioterapia & 33 \\
\hline Fonoaudiologia & 42 \\
\hline Formação Geral & 33 \\
\hline Medicina & 28 \\
\hline Medicina Veterinária & 45 \\
\hline Nutrição & 52 \\
\hline Odontologia & 48 \\
\hline Zootecnia & 55 \\
\hline \multicolumn{1}{c|}{ GERAL } & 43 \\
\hline & \\
\hline
\end{tabular}

Fonte. (INEP, 2021).

Tendo em vista essas discussões e análises avaliadas como pertinentes, algumas intervenções pedagógicas poderiam contribuir com esse fluxo de itens no BNI-ENADE, de tal modo que, o fluxo de entrada de itens seja maior que o fluxo de saída de itens desse banco. Deve-se levar em consideração que, em função da produção de novos conhecimentos, alguns itens desse banco podem se tornar obsoletos. Outro fator que pode interferir nessa "validade" de itens é a atualização nos sistemas normativos, que podem trazer transtornos a itens que levam em consideração normas específicas da área e/ou normas gerais, além das reformas que acontecem no sistema educacional superior do país. 
A expectativa de averiguar falhas nos métodos, nas metodologias, na proficiência do elaborador e/ou revisor, ou mesmo na complexidade natural desses tipos de itens. Há evidência de que possíveis falhas estão mais próximas dos processos de elaboração e/ou revisão desses tipos de itens do que dos processos pedagógicos envolvidos no curso de capacitação. Outra evidência relevante que pode ser observada é que os itens trabalhados pelos docentes em suas práticas pedagógicas distanciam-se dos tipos de itens de avaliação em larga escala. A falta de experiência com este tipo de item pode ser um fator a ser observado e trabalhado na revisão da prática pedagógica desses docentes.

Uma primeira intervenção pedagógica seria a constituição de uma equipe de docentes de cada curso e/ou área de conhecimento para uma análise detalhada de todo conteúdo de itens contido no BNI-ENADE, para que, assim, se possa ter uma leitura precisa do quantitativo de itens que há em perfeita condições de uso. Com isso, poderia se efetivar uma "limpeza" do banco tendo um real conhecimento da situação dos itens armazenados nesse banco.

Uma segunda intervenção pedagógica seria a efetivação do curso de capacitação no formato continuo, iniciando pelos cursos e/ou áreas que estão em maior risco de abastecimentos de seus respectivos armazenamentos de itens. Além desse propósito, atenderia também à agenda dos professores, pois muitas das vezes, suas participações nos processos de elaboração de itens são prejudicadas em função de suas atuações na docência nos referidos cursos.

Por último, poderia se criar um canal com grupos de IES para atendimentos em formatos de encontros, simpósios, workshops, webinars, dentre outros, para esclarecimentos e orientações dos procedimentos necessários para a construção de itens de qualidade. Com isso, poder-se-ia atrair mais participantes nos processos de elaboração de itens para o BNI-ENADE, com possiblidades reais de aumento da eficiência desse banco de itens.

\section{Conclusão}

$\mathrm{Na}$ elaboração deste trabalho, a análise e a interpretação de dados oficiais disponibilizados pelo INEP possibilitaram uma análise descritiva numa visão qualitativa e quantitativa. As evidências apontaram para uma expectativa inicial de que, esses dados e informações, retratassem de fato a realidade do BNI-ENADE em 2019. Com isso, ao efetuar comparações entre as eficiências dos cursos e área, foi possível identificar a problemática da eficiência em alguns cursos.

Com isso, o que levou ao questionamento: que medidas pedagógicas poderiam contribuir com melhorias nos processos de produção de itens implicando em melhor aproveitamento deles para o BNI-ENADE, pôde-şe averiguar a partir das análises de dados disponibilizados pelo INEP. Dentro dessa problemática, foi possível atingir o principal objetivo desse estudo: propor medidas pedagógicas que possam trazer melhorias no aproveitamento de itens para o banco nacional de itens.

As medidas que vêm sendo adotas pela gestão do BNI-ENADE através da Diretoria de Avaliação da Educação Superior (DAES) do INEP, demostram um esforço no sentido de atender as necessidades de abastecimento desse banco de itens. As medidas adotadas, na opção em estender esse abastecimento, as chamadas públicas têm contribuído para um número cada vez maior de colaboradores nos processos de elaboração e revisão de itens.

Por fim, considera-se que este estudo apresentou sua linha de contorno nos limites de dados apresentados pelo órgão responsável pelo BNI-ENADE. Nesse sentido, dificuldades na comparação com outras fontes de dados nos períodos 
pertinentes, como por exemplo, as variáveis ora analisadas que não têm as mesmas conotações, sendo definidas de modo arbitrário conforme a conveniência do estudo, como taxa de eficiência de itens do BNI-ENADE, por exemplo. Assim, estudos futuros poderiam aprofundar ou mesmo dar novas dimensões de análises pertinentes sobre a comparabilidade com outras edições do ENADE; custo efetivo dos processos dos bancos de itens do INEP e, assim, estender o entendimento da problemática de demanda do aumento de itens aceitos (aprovados) para esses bancos de itens. Além disso, apontar outros meios que venham a contribuir com a eficiência ou deficiência de itens de qualidades para compor as avaliações em larga escala.

\section{Referências}

BRASIL. Casa Civil. Lei no 10.861, de 14 de abril de 2004. Institui o Sistema Nacional de Avaliação da Educação Superior - SINAES. Disponível em: http://www.planalto.gov.br/ccivil 03/ ato2004-2006/2004/lei/l10.861.htm. Acesso em: 10 mai. 2019.

BRASIL. Ministério da Educação. Cadastro do BNI. Disponível em: http://portal.mec.gov.br/component/tags/tag/35017-banco-nacional-de-itens . Acesso em 11 de jul. 2020.

CAMPOS, F. C. S. Elaboração da prova do ENADE e no modelo do banco nacional de itens. Dissertação (Mestrado - Programa de pós-graduação profissional em gestão e avaliação da educação pública. Área de concentração: Centro de Políticas Públicas e Avaliação da Educação) Faculdade de Educação - CAEd/UFJF. Juiz de Fora - MG, 2013.

CERRI, R. Palestra na PUC-Campinas: BNI ENADE. Disponível em: https://www.puc-campinas.edu.br/wp-content/uploads/2016/04/proavi-palestra-sobrebni-seminarios-enade2014.pdf. Acesso em: 13 de jun. 2019.

INEP. Guia BNI - DAEB. Guia de elaboração e revisão de itens. v. 1. Brasília: INEP, 2010.

INEP. Edital de chamada pública. Cadastro de elaboradores e revisores de itens da Educação Superior (Ceres) do Banco Nacional de itens da Educação Superior (BNI - ES). Brasília: INEP. 2019a.

INEP. ENADE. Disponível em: http://portal.inep.gov.br/enade. Acesso em: 11 de ago. 2019b.

INEP. Guia BNI. Disponível em: http://inep.gov.br/guia-bni1. Acesso em: 10 de jul. 2019C.

INEP. O que é o BNI. Disponível em: http://inep.gov.br/banco-nacional-de-itens. Acesso em: 11 de jul. 2019d.

INEP. O que é o ENADE. Disponível em: http://portal.inep.gov.br/enade . Acesso em: 11 de ago. 2019e.

INEP. Guia BNI - atualizado em 19 de fevereiro de 2020. Disponível em: http://inep.gov.br/guia-bni1. Acesso em: 10 de mai. 2020.

INEP. Produção de itens para prova ENADE. Manifestação Protocolo: ํo 23546.025418/2021-09. Brasília: INEP, 2021.

SOARES, M. N. T. HORA, P. M. CASEIRO, L. O Banco Nacional de Itens do ENADE: iniciativa para democratização e avanços nos processos da avaliação da Educação Superior. 2 Simpósio Avaliação da Educação Superior. Porto Alegre, 2016. 